\title{
Oromandibular-limb hypogenesis syndrome
}

INSERM

\section{Source}

INSERM. (1999). Orphanet: an online rare disease and orphan drug data base.

Oromandibular-limb hypogenesis syndrome. ORPHA:2749

Oromandibular-limb hypogenesis syndromes (OLHS) are a group of dysmorphic complexes (including Charlie M syndrome, Hanhart syndrome and glossopalatine ankylosis; see these terms) characterized by the association of severe asymmetric limb defects (primarily involving distal segments) and abnormalities of the oral cavity and mandible (hypoglossia, aglossia, micrognathia, glossopalatine ankylosis, cleft palate, and gingival anomalies). 